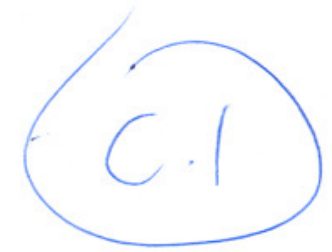

\title{
REPRESENTATION OF PURE-FLUID COEXISTENCE CURVES BY SERIES EXPANSION*
}

\author{
by \\ John M. Kincaid \\ Department of Mechanical Engineering \\ SUNY at Stony Brook \\ New York, New York 11794 \\ and \\ Brad Tooker and George Stell \\ Department of Chemistry \\ SUNY at Stony Brook \\ New York, New York 11794 \\ SUSB CEAS Report No. 542 February 1989)
}

*Work supported by the Office of Basic Energy Sciences, U. S. Department of Energy. under Grants No. DE-FG02-87ER13648 and DE-FG02-88ER13850. 


\begin{abstract}
We give a systematic recipe for constructing the coexistence curve associated with a pure fluid described by an analytic equation of state. The novelty of our result lies not in its theoretical basis, which is well-known, but in the high degree of accuracy that it will routinely yield over a broad range of density and temperature for a relatively modest expenditure of computing effort. The method is illustrated by applying our general solution to four widely-known model equations of state: van der Waals, Dieterici, Soave-Redlich-Kwong, and Carnahan-Starling with van der Waals tail term. These models show a considerable diversity of coexistence-curve shapes, and our method yields accurate representations for each model. An investigation of the representation of experimental coexistence curves that exhibit pronounced "non-classical" behavior over an appreciable range of densities is also initiated.
\end{abstract}




\section{INTRODUCTION.}

The Maxwell equal-area construction for pressure-volume isotherms is usually encountered early in one's study of thermodynamics. Typically, the relatively few who are called upon to actually implement the construction with precision for some reasonably realistic equation of state are initially surprised and chagrinned to find how difficult it is to do so, especially as one goes to lower and lower temperatures where there is increasing asymmetry in the shape of the two "van der Waals loops", the low-density loop spreading over an awkwardly large volume range. Perhaps at this point one astutely observes that there is an equivalent construction on the chemical potential versus density that is generally easier to implement because it is more symmetric, with the loops less spread out. Or perhaps it is suggested that the equivalent construction that involves locating the crossing of isotherm-segments when one plots chemical potential versus pressure may be easier to handle, at least as long as the crossing lines are not almost parallel.

Such observations and suggestions are helpful and useful, but even when they are exploited, it is not hard for a serious student of thermodynamics to conclude that the task of locating phase boundaries is akin to coming down with a bad cold — some traditional treatments seem more effective than others, but no matter which ones are used, a certain amount of tedious misery must be endured.

These reflections suggest that dispite the venerability of the problem at hand, there may still be a real market for a systematic coexistence-curve algorithm of wide applicability and reliability. The subject of this paper is such an algorithm. 
For the class of one-component fluids described by analytic expressions ${ }^{1}$ for pressure and chemical potential (in terms of density and temperature) we derive an analytic representation of the coexistence curve. Our method has its origin in the series-expansion techniques developed recently for calculating the dew/bubble curves of multicomponent and polydisperse fluids. ${ }^{2-5}$ Given the pressure, $p$, as a function of temperature, $\mathrm{T}$, and density, $\rho$, we find that the coexistence curve may be represented by the series

$$
\mathrm{T}_{\mathrm{S}}=\mathrm{T}_{\mathrm{C}}+\sum_{\mathrm{i}=2}^{\infty} \mathrm{T}_{\mathrm{i}}\left(\rho-\rho_{\mathrm{c}}\right)^{\mathrm{i}}
$$

where the coexistance curve is the locus of points $\left(\rho, \mathrm{T}_{\mathrm{S}}\right), \mathrm{T}_{\mathrm{C}}$ is the critical temperature, and $\rho_{\mathrm{C}}$ is the critical density; $\left\{\mathrm{T}_{\mathrm{i}}\right\}$ are constants that depend on derivatives of the pressure with respect to temperature and density, evaluated at the critical point.

The series representation of $\mathrm{T}_{\mathrm{S}}(\rho)$ can be used to determine series representations for all thermodynamic properties of the fluid on the coexistence curve. For instance, the saturation pressure, $\mathrm{p}_{\mathrm{S}}\left(\mathrm{T}_{\mathrm{S}}\right)$, and the latent heat, $\mathrm{h}\left(\mathrm{T}_{\mathrm{S}}\right)$, may be easily calculated, as well as $\rho_{\ell}\left(\mathrm{T}_{\mathrm{S}}\right)$ and $\rho_{\mathrm{g}}\left(\mathrm{T}_{\mathrm{S}}\right)$, where $\rho_{\ell}$ and $\rho_{\mathrm{g}}$ are the densities of the liquid and gas phases, respectively.

We have not evaluated the complete set of coefficients $\left\{\mathrm{T}_{\mathrm{i}}\right\}$, but only $\left\{\mathrm{T}_{\mathrm{i}}, \mathrm{i}=\right.$ $2, \ldots, 13\}$. Thus we have obtained only an approximate representation of the coexistence curve. However, we find that by forming Padé approximants ${ }^{6}$ from the truncated series, very accurate and compact approximations are obtained.

Series expansions have been used to determine mean-field phase boundaries of fluids and magnetic systems near the critical point for many years. ${ }^{7,8,9}$ Our results may be 
viewed as a systematic extension of the well-known methods used in such studies. It came as something of a surprise to us that a globally accurate representation of the coexistence curve could be obtained by systematically extending the relevant series somewhat farther than earlier workers. This extension is not simply an embellishment that adds somewhat more accuracy to these earlier results. Although many of the hallmarks of "non-classical" critical behavior are important only in a small neighborhood about the critical point, a few appear to dominate the thermodynamic behavior of many fluids in a more global way. A notable example relevant to our study here is the shape of the coexistence curve in $(\rho, \mathrm{T})$ space about the point $\left(\rho_{\mathrm{C}}, \mathrm{T}_{\mathrm{C}}\right)$; the "non-classical" form $\mathrm{T}_{\mathrm{C}}-\mathrm{T}_{\mathrm{S}}=$ const $\times\left|\rho-\rho_{\mathrm{C}}\right|^{3}$ has long been known to be a far better approximation to the coexistence-curve shape than the leading term of the analytical expansion $\mathrm{T}_{\mathrm{S}}-\mathrm{T}_{\mathrm{C}}=\mathrm{T}_{2}\left(\rho-\rho_{\mathrm{C}}\right)^{2}+\mathrm{T}_{3}\left(\rho-\rho_{\mathrm{C}}\right)^{3}+\cdots$ that follows from Eq. (1). However, as we discuss at the end of Section III with the addition of some illustrative examples, it turns out that as soon as one uses 8 or more terms in the right-hand side of this expansion, one can fit the coexistence for fluid (and magnetic) systems with overall precision comparable to that obtained, for example, by the famous nonanalytic "Guggenheim fit" [Eqs. (60) and (61) below]. Thus our method promises to be able to cope quantitatively with the most important "non-classical" thermodynamic effects (except in a very small neighborhood of the critical point) despite its analytic nature. One can not use an analytic expansion of this form with only two or three terms and hope to attain quantitatively reasonable results, however.

Our results will be especially useful for two-types of work: fluid-process design and model-fluid investigation. In the case of fluid-process design our method provides compact (i.e., easy to evaluate), accurate expressions for all two-phase quantities of interest, making it easy to incorporate the correct two-phase properties into process simulation codes. In particular it provides a representation of the two-phase region that is 
consistent with the equation of state of the fluid. In the case of model-fluid development our method eliminates the need for time consuming phase-equilibrium calculations when one is exploring the properties of a particular model fluid. Since it is possible to determine the $\left\{\mathrm{T}_{\mathrm{i}}\right\}$ as functions of various parameters in the equation of state, one may easily study the effect that those parameters have on the phase boundaries of the model. In both fluid-process and model-fluid work, the great bulk of the thermodynamic descriptions currently being used yield representations of pressure and chemical potential that lend themselves to our technique.

In Sec. II we show in detail how the coefficients $\left\{\mathrm{T}_{\mathrm{i}}\right\}$ are determined for an equation of state of the analytic form we consider. Then in Sec. III we apply the method to four model equations of state: van der Waals, Dieterici, Soave-Redlich-Kwong, and the so-called Carnahan-Starling with a van der Waals "tail". We describe how the coefficients $\left\{\mathrm{T}_{\mathrm{i}}\right\}$ may be used to calculate other thermodynamic properties along the coexistence curve, and compare the series-expansion representation to numerical solutions obtained using the equal-areas rule. We find that Padé approximants of the series expansions provide very accurate representations of coexistence-curve properties. Finally, we briefly discuss the way in which our method promises to be useful in fitting experimental data even in cases in which it is important to approximate with quantitative accuracy the "non-classical" nature of the coexistence curve about the critical point over a substantial range of density. 


\section{DETERMINATION OF $\left\{\mathrm{T}_{\mathrm{i}}\right\}$.}

In this Section we solve the two-phase equilibrium conditions using the method of series expansion. The equations that determine the coefficients $\left\{T_{i}, y_{i}\right\}$ are derived in part A; the method of solution is described in part B.

\section{A. The Equilibrium Conditions.}

The pressure $\mathrm{p}$ and chemical potential $\mu$ of a one-component fluid depend on the temperature $\mathrm{T}$ and number density $\rho$

$$
\mathrm{p}=\mathrm{p}(\mathrm{T}, \rho)
$$

and

$$
\mu=\mu(\mathrm{T}, \rho)
$$

We shall assume that the units for $\mathrm{T}$ and $\rho$ have been chosen so that at the critical point $\mathrm{T}_{\mathrm{C}}=1$ and $\rho_{\mathrm{C}}=1$, where the critical point $\left(\mathrm{T}_{\mathrm{c}}, \rho_{\mathrm{C}}\right)$ is determined by the equations

$$
(\partial \mathrm{p} / \partial \rho)_{\mathrm{T}}=0
$$

and

$$
\left(\partial^{2} \mathrm{p} / \partial \rho^{2}\right)_{\mathrm{T}}=0
$$

In the neighborhood of the critical point we may represent $\mathrm{p}$ and $\mu$ by their Taylor series expansions about $\left(\mathrm{T}_{\mathrm{c}}, \rho_{\mathrm{c}}\right)$ 


$$
\begin{aligned}
& \mathrm{p}(\mathrm{T}, \rho)=\sum_{\mathrm{n}=0}^{\infty} \sum_{\mathrm{k}=0}^{\infty} \mathrm{q}_{\mathrm{k}, \mathrm{n}} \delta \rho^{\mathrm{k}} \delta \mathrm{T}^{\mathrm{n}} \\
& \mu(\mathrm{T}, \rho)=\sum_{\mathrm{n}=0}^{\infty} \sum_{\mathrm{k}=0}^{\infty} \mathrm{c}_{\mathrm{k}, \mathrm{n}} \delta \rho^{\mathrm{k}} \delta \mathrm{T}^{\mathrm{n}},
\end{aligned}
$$

where $\delta \rho=\rho-\rho_{c}, \delta \mathrm{T}=\mathrm{T}-\mathrm{T}_{\mathrm{c}}$,

$$
\begin{aligned}
& \mathrm{q}_{\mathrm{k}, \mathrm{n}}=\frac{\partial^{\mathrm{k}+\mathrm{n}} \mathrm{p}}{\partial \rho^{\mathrm{k}} \partial \mathrm{T}^{\mathrm{n}}} /(\mathrm{k} ! \mathrm{n} !), \\
& \mathrm{c}_{\mathrm{k}, \mathrm{n}}=\frac{\partial^{\mathrm{k}+\mathrm{n}} \mu}{\partial \rho^{\mathrm{k}} \partial \mathrm{T}^{\mathrm{n}}} /(\mathrm{k} ! \mathrm{n} !),
\end{aligned}
$$

and all derivatives are evaluated at $\mathrm{T}=\mathrm{T}_{\mathrm{c}}, \rho=\rho_{\mathrm{c}}$. In view of Eqs. (4) and (5), $\mathrm{q}_{1,0}=\mathrm{q}_{2,0}=0$.

Two phases, with densities $\mathrm{x}$ and $\mathrm{y}$, are in equilibrium at the temperature $\mathrm{T}$ if

$$
\mathrm{p}(\mathrm{T}, \mathrm{x})-\mathrm{p}(\mathrm{T}, \mathrm{y})=0
$$

and

$$
\mu(\mathrm{T}, \mathrm{x})-\mu(\mathrm{T}, \mathrm{y})=0
$$

Using the series representations for p and $\mu$ [Eqs. (6) and (7)], Eqs. (10) and (11) become

$$
\sum_{n=0}^{\infty} \sum_{k=1}^{\infty} \mathrm{q}_{\mathrm{k}, \mathrm{n}}\left(\delta \mathrm{x}^{\mathrm{k}}-\delta \mathrm{y}^{\mathrm{k}}\right) \delta \mathrm{T}^{\mathrm{n}}=0
$$


and

$$
\sum_{n=0}^{\infty} \sum_{k=1}^{\infty} c_{k, n}\left(\delta x^{k}-\delta y^{k}\right) \delta T^{n}=0
$$

(Note that the $\mathrm{k}=0$ terms have been dropped since $\delta \mathrm{x}^{0}-\delta \mathrm{y}^{0}=0$.) Eqs. (12) and (13) have the obvious solution $\mathrm{x}=\mathrm{y}$, which for our purpose we consider to be trivial. Since

$$
a^{k}-b^{k}=(a-b) \sum_{\ell=1}^{k} a^{k-\ell} b^{\ell-1}
$$

the nontrivial solutions of the equilibrium conditions [Eqs. (12) and (13)] satisfy

$$
\sum_{n=0}^{\infty} \sum_{k=1}^{\infty} \mathrm{q}_{\mathrm{k}, \mathrm{n}} \sum_{\ell=1}^{\mathrm{k}} \delta \mathrm{x}^{\mathrm{k}-\ell} \delta \mathrm{y}^{\ell-1} \delta \mathrm{T}^{\mathrm{n}}=0
$$

and

$$
\sum_{n=0}^{\infty} \sum_{k=1}^{\infty} c_{k, n} \sum_{\ell=1}^{k} \delta x^{k-\ell} \delta y^{\ell-1} \delta T^{n}=0
$$

The coefficients $c_{k, n}$ and $q_{k, n}$ are related by the following equation, which may be derived using the Gibbs-Duhem equation (see Appendix 1)

$$
c_{k, n}=\sum_{j=0}^{k-1} \frac{(-1)^{j}(k-j)}{k} q_{k-j, n}
$$

Substituting Eq. (17) into Eq. (16) we obtain 


$$
\sum_{n=0}^{\infty} \sum_{k=1}^{\infty} \sum_{j=0}^{k-1} \frac{(-1)^{j}(k-j)}{k} q_{k-j, n} \sum_{\ell=1}^{k} \delta x^{k-\ell} \delta y{ }^{\ell-1} \delta T^{n}=0
$$

In summary, the two-phase equilibrium conditions are

$$
\begin{aligned}
& \sum_{n=0}^{\infty} \sum_{k=1}^{\infty} \mathrm{q}_{\mathrm{k}, \mathrm{n}} \sum_{\ell=1}^{\mathrm{k}} \delta \mathrm{x}^{\mathrm{k}-\ell} \delta \mathrm{y}^{\ell-1} \delta \mathrm{T}^{\mathrm{n}}=0 . \\
& \sum_{\mathrm{n}=0}^{\infty} \sum_{\mathrm{k}=1}^{\infty} \sum_{\mathrm{j}=0}^{\mathrm{k}-1} \frac{(-1)^{\mathrm{j}}(\mathrm{k}-\mathrm{j})}{\mathrm{k}} \mathrm{q}_{\mathrm{k}-\mathrm{j}, \mathrm{n} \sum_{\ell=1}^{\mathrm{k}} \delta \mathrm{x}^{\mathrm{k}-\ell} \delta \mathrm{y}}^{\ell-1} \delta \mathrm{T}^{\mathrm{n}}=0 .
\end{aligned}
$$

The equilibrium conditions are solved by finding $\mathrm{T}$ and $\mathrm{y}$ as functions of $\mathrm{x}$. Noting that the top of the coexistence curve is parabolic in the density-temperature plane, we set

$$
\delta \mathrm{T}=\sum_{\mathrm{j}=2}^{\infty} \mathrm{T}_{\mathrm{j}} \delta \mathrm{x}^{\mathrm{j}}
$$

and

$$
\delta y=-\delta x+\sum_{j=2}^{\infty} y_{j} \delta x^{j}
$$

[Note: it will turn out that $y_{1}=-1$ so for convenience we make use of that fact now.] 
Solving the equilibrium conditions is then reduced to the task of finding the coefficients $\left\{T_{j}, y_{j}\right\}$.

We begin by denoting

$$
\delta \mathrm{T}^{\mathrm{n}}=\sum_{\mathrm{s}=2 \mathrm{n}}^{\infty} \lambda_{\mathrm{n}, \mathrm{s}} \delta \mathrm{x}^{\mathrm{s}}
$$

and

$$
\delta y^{\ell-1}=\sum_{r=\ell-1}^{\infty} \theta_{\ell-1, r^{\delta}}{ }^{r} .
$$

Here $\lambda_{n, S}$ depends on the coefficients $\left\{T_{j}\right\}$ and $\theta_{\ell-1, r}$ depends on the coefficients $\left\{y_{j}\right\}$. In Appendix 2 we give the formal expressions for $\lambda_{\mathrm{n}, \mathrm{s}}$ and $\theta_{\ell-1, \mathrm{r}}$. [Note that $\lambda_{0,0}=\theta_{0,0}=1$. $\lambda_{\mathrm{n}, \mathrm{s}}=0$ for $\mathrm{s}<2 \mathrm{n}$, and $\theta_{\ell-1, \mathrm{r}}=0$ for $\mathrm{r}<\ell-1$.] Substituting Eqs. (23) and (24) into Eqs. (19) and (20) we obtain

$$
\begin{aligned}
& \sum_{\mathrm{n}=0}^{\infty} \sum_{\mathrm{k}=1}^{\infty} \mathrm{q}_{\mathrm{k}, \mathrm{n}} \sum_{\ell=1}^{\mathrm{k}} \sum_{\mathrm{r}=\ell-1}^{\infty} \theta_{\ell-1, \mathrm{r}} \sum_{\mathrm{s}=2 \mathrm{n}}^{\infty} \lambda_{\mathrm{n}, \mathrm{s}} \delta \mathrm{x}^{\mathrm{k}+\mathrm{r}+\mathrm{s}-\ell}=0 \\
& \sum_{\mathrm{n}=0}^{\infty} \sum_{\mathrm{k}=1}^{\infty} \sum_{\mathrm{j}=0}^{\mathrm{k}-1} \frac{(-1)^{\mathrm{j}}(\mathrm{k}-\mathrm{j})}{\mathrm{k}} \mathrm{q}_{\mathrm{k}-\mathrm{j}, \mathrm{n}} \sum_{\ell=1}^{\mathrm{k}} \sum_{\mathrm{r}=\ell-1}^{\infty} \theta_{\ell-1, \mathrm{r}} \sum_{\mathrm{s}=2 \mathrm{n}}^{\infty} \lambda_{\mathrm{n}, \mathrm{s}} \delta \mathrm{x}^{\mathrm{k}+\mathrm{r}+\mathrm{s}-\ell}=0 .
\end{aligned}
$$

When $\mathrm{j}=0$, Eq. (26) becomes identical to Eq. (25). It is convenient therefore to eliminate that degeneracy by replacing Eq. (26) with the difference between Eqs. (26) and (25). Thus we express the equilibrium conditions by 


$$
\sum_{n=0}^{\infty} \sum_{k=1}^{\infty} \mathrm{q}_{\mathrm{k}, \mathrm{n}} \sum_{\ell=1}^{\mathrm{k}} \sum_{\mathrm{r}=\ell-1}^{\infty} \theta_{\ell-1, \mathrm{r}} \sum_{\mathrm{s}=2 \mathrm{n}}^{\infty} \lambda_{\mathrm{n}, \mathrm{s}} \delta \mathrm{x}^{\mathrm{k}+\mathrm{r}+\mathrm{s}-\ell}=0
$$

and

$$
\sum_{n=0}^{\infty} \sum_{k=1}^{\infty}\left[\sum_{j=0}^{k-1} \frac{(-1)^{j}(k-j)}{k} q_{k-j, n}-q_{k, n}\right]_{\ell=1}^{k} \sum_{r=\ell-1}^{\infty} \theta_{\ell-1, r} \sum_{s=2 n}^{\infty} \lambda_{n, s} \delta x^{k+r+s-\ell}=0
$$

As a practical matter, we will not solve these equations for all the coefficients, but only for those coefficients that occur in these equations through order $\delta \mathrm{x}^{\mathrm{m}}$. For convenience let us choose $\mathrm{m}$ to be even and let $\mathrm{M}=\mathrm{m} / 2$. Then for a specified $\mathrm{m}$ (14 is the largest value we have used) the equilibrium conditions are

$$
\sum_{n=0}^{\mathrm{M}} \sum_{\mathrm{s}=2 \mathrm{n}}^{\mathrm{m}} \lambda_{\mathrm{n}, \mathrm{s}} \sum_{\mathrm{k}=1}^{\mathrm{m}+1-\mathrm{s}} \mathrm{q}_{\mathrm{k}, \mathrm{n}} \sum_{\ell=1}^{\mathrm{k}} \sum_{\mathrm{r}=\ell-1}^{\mathrm{m}-\mathrm{k}-\mathrm{s}+\ell} \theta_{\ell-1, \mathrm{r}} \delta \mathrm{x}^{\mathrm{k}+\mathrm{r}+\mathrm{s}-\ell}=0
$$

and

$$
\sum_{n=0}^{M} \sum_{s=2 n}^{m} \lambda_{n, s} \sum_{k=1}^{m+1-s} \sum_{j=1}^{k-1} \frac{(-1)^{j}(k-j)}{k} q_{k-j, n} \sum_{\ell=1}^{k} \sum_{r=\ell-1}^{m-k-s+\ell} \theta_{\ell-1, r} \delta x^{k+r+s-\ell}=0
$$

\section{B. Solution Method.}

To solve these equations, MACSYMA is used to evaluate the $\lambda$ 's and $\theta^{\prime}$ s and then expand the summations in Eqs. (29) and (30) into the forms 


$$
\sum_{i=2}^{m} \operatorname{PCOEF}[i] \delta \mathrm{x}^{\mathrm{i}}=0
$$

and

$$
\sum_{i=2}^{m} \operatorname{MCOEF}[i] \delta x^{i}=0
$$

and therefore the equilibrium conditions become

$$
\operatorname{PCOEF}[\mathrm{i}]=0, \mathrm{i}=2, \ldots, \mathrm{m}
$$

and

$$
\operatorname{MCOEF}[\mathrm{i}]=0 \quad, \mathrm{i}=2, \ldots, \mathrm{m} .
$$

We find that $\mathrm{MCOEF}[2]$ and $\mathrm{MCOEF}[3]$ are equivalent to $\mathrm{PCOEF}[2]$ and $\mathrm{PCOEF}[3]$. PCOEF[i] is linear in $\mathrm{T}_{\mathrm{i}}$ and depends on all $\mathrm{T}_{\mathrm{j}}$ and $\mathrm{y}_{\mathrm{j}}, \mathrm{j}<\mathrm{i}$; MCOEF[i+2] is linear in $\mathrm{y}_{\mathrm{i}}$ and depends on all $\mathrm{T}_{\mathrm{j}}, \mathrm{j} \leq \mathrm{i}$, and all $\mathrm{y}_{\mathrm{j}}, \mathrm{j}<\mathrm{i}$. Thus one obtains first $\mathrm{T}_{2}$ by solving PCOEF[2] $=0$, then $\mathrm{y}_{2}$ by solving $\mathrm{MCOEF}[4]=0$, and so on until $\mathrm{T}_{\mathrm{m}-1}$ and $\mathrm{y}_{\mathrm{m}-2}$ are obtained.

In Table I we list the low-order coefficients. They depend on the derivatives, $q_{i, n}$, defined by Eq. (8). We find that to determine the coefficients up to $\mathrm{T}_{\mathrm{m}-1}$ and $\mathrm{y}_{\mathrm{m}-2}$ only $\mathrm{q}_{\mathrm{i}, \mathrm{n}}$ for $\mathrm{i}=1, \ldots, \mathrm{m}$ and $\mathrm{n}=0, \ldots,\left[\left[\frac{\mathrm{m}-1}{2}\right]\right]$ need to be evaluated. (Here $[[\ldots]]$ signifies the greatest integer less than.) Eqs. (4) and (5) imply that $\mathrm{q}_{1,0}=\mathrm{q}_{2,0}=0$.

It is interesting to note that the $\mathrm{T}_{\mathrm{i}}$ and $\mathrm{y}_{\mathrm{i}}$ are not entirely independent. Since $\mathrm{T}_{\mathrm{S}}(\mathrm{x})=\mathrm{T}_{\mathrm{S}}(\mathrm{y}(\mathrm{x}))$ we find that $\mathrm{T}_{3}=-\mathrm{T}_{2} \mathrm{y}_{2}, \mathrm{y}_{3}=-\mathrm{y}_{2}^{2}, \mathrm{~T}_{5}=-\mathrm{T}_{2} \mathrm{y}_{4}+2 \mathrm{~T}_{2} \mathrm{y}_{2}^{3}-2 \mathrm{~T}_{4} \mathrm{y}_{2}$, $y_{5}=2 y_{2}^{4}-3 y_{2} y_{4}$, etc. It may be possible to use these relations to simplify the calculation of $\left\{\mathrm{T}_{\mathrm{i}}, \mathrm{y}_{\mathrm{i}}\right\}$, although we did not make explicit use of these relations ships in the calculations reported here. 


\section{Application to Several Models.}

We shall examine here the series derived in the previous Section within the context of four representative model equations of state. We begin by showing how the coefficients $\left\{\mathrm{T}_{\mathrm{i}}\right\}$ and $\left\{\mathrm{y}_{\mathrm{i}}\right\}$ may be used to develop series for the liquid and vapor densities, $\rho_{\ell}$ and $\rho_{\mathrm{g}}$, the saturation pressure, $\mathrm{p}_{\mathrm{S}}$, and the latent heat, $\mathrm{h}$, as functions of the temperature. These series, as well as the series for the saturation temperature as a function of density, are evaluated in III.B and compared to results obtained by numerically solving the equilibrium conditions. We find that the series representation is quite accurate near the critical point and that Padé approximants formed from these series are quite accurate over most of the saturation curve.

\section{A. Additional Coexistence Curve Series.}

The series coefficients $\left\{\mathrm{T}_{\mathrm{i}}\right\}$ can be used to construct the coexistence curve, but it would, in many cases, be more convenient to represent the curve by giving the liquid and vapor densities, $\rho_{\ell}$ and $\rho_{\mathrm{g}}$, as functions of $\mathrm{T}_{\mathrm{S}}$. Also, series for the saturation pressure, $\mathrm{p}_{\mathrm{S}}$, as a function of $\mathrm{T}_{\mathrm{S}}$ and the latent heat, $\mathrm{h}$, as a function of $\mathrm{T}_{\mathrm{S}}$ would be useful to have. Below we document the calculation of these additional series. For convenience we choose to work in units such that $\mathrm{T}_{\mathrm{C}}=1$ and $\rho_{\mathrm{C}}=1$.

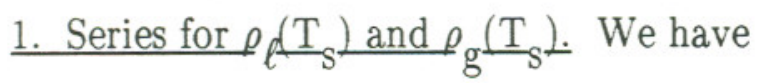

$$
\mathrm{T}_{\mathrm{S}}=1+\mathrm{T}_{2} \delta \rho^{2}+\mathrm{T}_{3} \delta \rho^{3}+\cdots
$$

where $\mathrm{T}_{2}<0$ and $\delta \rho=\rho-1$. Thus 


$$
\begin{aligned}
\mathrm{T}_{\mathrm{S}}-1=\delta \mathrm{T} & =\sum_{\mathrm{i}=2}^{\infty} \mathrm{T}_{\mathrm{i}} \delta \rho^{\mathrm{i}}, \\
& =\mathrm{T}_{2} \delta \rho^{2}\left[1+\frac{\mathrm{T}_{3}}{\mathrm{~T}_{2}} \delta \rho+\frac{\mathrm{T}_{4}}{\mathrm{~T}_{2}} \delta \rho^{2}+\cdots\right]
\end{aligned}
$$

or

$$
\delta \mathrm{T} / \mathrm{T}_{2}=\delta \rho^{2}\left[1+\frac{\mathrm{T}_{3}}{\mathrm{~T}_{2}} \delta \rho+\frac{\mathrm{T}_{4}}{\mathrm{~T}_{2}} \delta \rho^{2}+\cdots\right]
$$

Since $\delta \mathrm{T}<0$ and $\mathrm{T}_{2}<0, \delta \mathrm{T} / \mathrm{T}_{2}>0$. Taking the square root of both sides of Eq. (47) we obtain

$$
\mathrm{w}=|\delta \rho|\left[1+\frac{\mathrm{T}_{3}}{\mathrm{~T}_{2}} \delta \rho+\frac{\mathrm{T}_{4}}{\mathrm{~T}_{2}} \delta \rho^{2}+\cdots\right]^{1 / 2},
$$

where $\mathrm{w}=\left[\delta \mathrm{T} / \mathrm{T}_{2}\right]^{1 / 2}$. Expanding the right-hand-side of Eq. (48) in a Taylor series about $\delta \rho=0$ we obtain

$$
w=|\delta \rho|\left[1+\sum_{i=1}^{\infty} \mathrm{r}_{\mathrm{i}} \delta \rho^{\mathrm{i}}\right] .
$$

When $\rho=\rho_{\ell}$ (i.e., $\left.\delta \rho>0\right)$ we have

$$
\mathrm{w}=\delta \rho_{\ell}+\mathrm{r}_{1} \delta \rho_{\ell}^{2}+\mathrm{r}_{2} \delta \rho_{\ell}^{3}+\cdots=\sum_{\mathrm{i}=1}^{\infty} \mathrm{r}_{\mathrm{i}-1} \delta \rho_{\ell}^{\mathrm{i}},
$$

with $\mathrm{r}_{0}=1$; when $\rho=\rho_{\mathrm{g}}$ (i.e., $\left.\delta \rho<0\right)$ we have 


$$
-\mathrm{w}=\delta \rho_{\mathrm{g}}+\mathrm{r}_{1} \delta \rho_{\mathrm{g}}^{2}+\mathrm{r}_{2} \delta \rho_{\mathrm{g}}^{3}+\cdots=\sum_{\mathrm{i}=1}^{\infty} \mathrm{r}_{\mathrm{i}-1} \delta \rho_{\mathrm{g}}^{\mathrm{i}} .
$$

Reverting Eqs. (50) and (51) to obtain series for $\rho_{\ell}$ and $\rho_{\mathrm{g}}$ in terms of w we obtain

$$
\rho_{\ell}=1+\sum_{j=1}^{\infty} s_{j} w^{j}
$$

and

$$
\rho_{g}=1+\sum_{j=1}^{\infty} s_{j}(-1)^{j} w^{j}
$$

2. The Saturation Curve Pressure, $\mathrm{p}_{\mathrm{S}^{-}}$. Since

$$
p=\sum_{i=0}^{\infty} \sum_{j=0}^{\infty} q_{i, j} \delta T^{j} \delta \rho^{i}
$$

where $\delta \mathrm{T}=\mathrm{T}-1$ and $\delta \rho=\rho-1$, if follows that

$$
\mathrm{p}_{\mathrm{s}}=\sum_{\mathrm{i}=0}^{\infty} \sum_{\mathrm{j}=0}^{\infty} \mathrm{q}_{\mathrm{i}, \mathrm{j}}\left[\sum_{\mathrm{k}=2}^{\infty} \mathrm{T}_{\mathrm{k}} \delta \rho^{\mathrm{k}}\right]^{\mathrm{j}} \delta \rho^{\mathrm{i}}
$$

Expanding the right hand side will lead to

$$
\mathrm{p}_{\mathrm{S}}=\sum_{\mathrm{i}=0}^{\infty} \overline{\mathrm{u}}_{\mathrm{i}} \delta \rho^{\mathrm{i}}
$$


Now, substituting either $\delta \rho=\sum_{\mathrm{j}=1}^{\infty} \mathrm{s}_{\mathrm{j}} \mathrm{w}^{\mathrm{j}}$ or $\delta \rho=\sum_{\mathrm{j}=1}^{\infty} \mathrm{s}_{\mathrm{j}}(-1)^{\mathrm{j}} \mathrm{w}^{\mathrm{j}}$ into Eq. (56) yields

$$
p_{S}=1+\sum_{j=1}^{\infty} u_{i} w^{i}
$$

We find that all coefficients $u_{i}=0$ when $\mathrm{i}$ is odd. Thus $\mathrm{p}_{\mathrm{S}}$ has an expansion in powers of $\delta \mathrm{T}_{\mathrm{S}}=\mathrm{T}_{\mathrm{S}}-1$

3. The Latent Heat. From the Clapeyron equation we have

$$
\mathrm{h}=\text { latent heat }=\mathrm{T}\left(\frac{1}{\rho_{\mathrm{g}}}-\frac{1}{\rho_{\ell}}\right)\left(\mathrm{dp}_{\mathrm{S}} / \mathrm{dT}_{\mathrm{S}}\right)
$$

To calculate $h$ all we have to do is differentiate $p_{S}$ with respect to $T_{S}$, substitute in the series for $\rho_{\mathrm{g}}$ and $\rho_{\ell}$ and expand Eq. (58) in a Taylor series about $\mathrm{T}=1$. Since $\mathrm{p}, \rho_{\mathrm{g}}\left(\mathrm{T}_{\mathrm{s}}\right)$. and $\rho_{\ell}\left(\mathrm{T}_{\mathrm{S}}\right)$ are series in $\mathrm{w}$, and $\mathrm{dw} / \mathrm{dT}_{\mathrm{S}}=1 /\left(2 \mathrm{~T}_{2} \mathrm{w}\right)$ we have

$$
\mathrm{h} / \mathrm{T}=\frac{\left(\rho_{\ell}-\rho_{\mathrm{g}}\right)\left(\mathrm{dp}_{\mathrm{S}} / \mathrm{dw}\right)}{2 \mathrm{~T}_{2} \mathrm{w} \rho_{\ell} \rho_{\mathrm{g}}}
$$

We note that since the series for $\mathrm{p}_{\mathrm{S}}$ may be reverted to yield $\mathrm{T}_{\mathrm{S}}$ as series in $\left(\mathrm{p}_{\mathrm{S}}-1\right)$, it is also possible to obtain $\rho_{\ell}, \rho_{\mathrm{g}}$, and $\mathrm{h}$ as functions of $\mathrm{p}_{\mathrm{S}}$. 


\section{B. Comparison to Numerical Solutions of the Equilibrium Conditions.}

We have assumed that $\mathrm{T}_{\mathrm{C}}=1$ and $\rho_{\mathrm{C}}=1$ so the equation of state for each model considered must be appropriately scaled before the $\mathrm{q}_{\mathrm{i}, \mathrm{n}}$ are evaluated. Given the $\left\{\mathrm{q}_{\mathrm{i}, \mathrm{n}}\right\}$ the coefficients $\left\{T_{j}, y_{j}\right\}$ may be evaluated. Since the expressions for $\left\{T_{j}, y_{j}\right\}$ contain many terms for large $\mathrm{j}$, the evaluation must be carried out carefully to avoid loss of precision. Using MACSYMA to evaluate $\left\{\mathrm{T}_{\mathrm{j}}, \mathrm{y}_{\mathrm{j}}\right\}$ is complicated when the $\mathrm{q}_{\mathrm{i}, \mathrm{n}}$ are irrational numbers; MACSYMA does not handle irrational numbers very well. Of the models we examine below only for the van der Waals and Dieterici models are the $\mathrm{q}_{\mathrm{i}, \mathrm{n}}$ rational numbers.

In Table II we list the equations of state of the four models for which we have calculated the series coefficients. We chose these equations of state because they are representative of the types of equations used to model simple fluids and for these models the shape of the coexistence curves are quite distinct from each other. Each of these equations of state depend on two microscopic parameters, "b" (or $\sigma$ ) and "a". ("b" and $\sigma$ represent the excluded volume of a particle and "a" represents the mean attractive potential energy of two particles.) For the models we consider here these parameters are scaled out of the equations of state when reduced variables are introduced. This feature makes the evaluation of the $\left\{\mathrm{q}_{\mathrm{i}, \mathrm{n}}\right\}$ relatively straightforward, but it is not a necessary feature; more complicated equations of state can be used. (We note, however, that it becomes more difficult to evaluate the $q_{i, n}$ when the equation of state contains many additional constants.)

In Table III we list the coefficients $\left\{\mathrm{T}_{\mathrm{i}}, \mathrm{i}=2,13\right\}$ for each model. (For the van der Waals model, which has a particularly simple form, $\mathrm{T}_{14}$ and $\mathrm{T}_{15}$ are also given.)

The coexistence curve, as represented by the series expansion $\mathrm{T}_{\mathrm{S}}(\rho)$, is shown in Figs. 1-4 for each of the models considered. In those figures the solid dots represent 
numerical solutions obtained using the equal areas rule; the series expansions are represented by the dotted curves; the solid curve represents a Padé approximant formed from the series expansion. In each case the series are quite accurate in the reduced temperature range $(0.9,1.0)$; the Padé approximant formed from the series is accurate over a much broader range of temperatures. For the van der Waals model it was possible to construct a useful Padé approximant that had the correct $\mathrm{T}=0$ solution $\left(\rho_{\ell}=3, \rho_{\mathrm{g}}=0\right)$. For the other models we found that imposing the correct values at $\mathrm{T}=0$ gave rise to singularities on other portions of the coexistence curve.

In practical applications, of course, the vapor-liquid coexistence curve will terminate at the triple point, below which there will be vapor-solid equilibrium. Thus the vapor-liquid coexistence curve at very low temperatures is not generally of interest. For the model using the Carnahan-Starling equation plus a van der Waals tail term, which is an excellent approximation to a system of hard spheres with a weak, long-range attractive potential, we estimate the reduced triple-point temperature to be 0.4625 and the reduced triple-point densities to be $2.1390 \times 10^{-3}, 3.6218$, and $4.4075 .^{10}$ The Padé approximant shown in Fig. 4 was constructed to give the correct temperature at the triple-point densities. This Padé gives an excellent representation of the entire liquid-vapor coexistence curve; the relative errors are listed in Table IV.

The series coefficients for $\rho_{\ell}(\mathrm{T}), \rho_{\mathrm{g}}(\mathrm{T}), \mathrm{p}_{\mathrm{S}}(\mathrm{T})$, and $\mathrm{h}(\mathrm{T})$ have been calculated for each of the four models considered here. We find that the Padé approximants formed from these series are accurate to better than $1 \%$ in the reduced temperature range $(0.65,1)$. The relative errors of the Padé approximants for the CS + vdW model are listed in Table V. For most purposes these Padé approximants may be considered exact: the largest relative error between the critical point and triple point $(\mathrm{T} \epsilon[0.4625,1])$ is 0.0074 . 
We remark that when the equations of state considered here are used to model real fluids, the parameters "b" (or $\sigma$ ) and "a" are often temperature dependent. The simplest way to deal with this additional complication is to remove these temperature dependent parameters from the equation of state by introducing a set of reduced variables $\mathrm{T}^{*}=\mathrm{T} \alpha(\mathrm{T})$ and $\rho^{*}=\rho \beta(\mathrm{T})$ (e.g., for the van der Waals model a good choice would be $\alpha(\mathrm{T})=27 \mathrm{Rb}(\mathrm{T}) /(8 \mathrm{a}(\mathrm{T}))$ and $\beta(\mathrm{T})=3 \mathrm{~b}(\mathrm{~T}))$, then evaluate the desired series-expansion coefficients, and form the Padé approximants as functions of the reduced variables. The representation of the real fluid's saturation properties is obtained by substituting $\mathrm{T} \alpha(\mathrm{T})$ for $\mathrm{T}^{*}$ and $\rho \beta(\mathrm{T})$ for $\rho^{*}$.

Most equations of state used to model real fluids are analytic functions in the neighborhood of the critical point; they exhibit so-called "classical" critical point properties. The methods we have described here apply to these equations of state. Real fluids, on the other hand, show a "non-classical" behavior, which indicates that the true equations of state are not analytic functions in a neighborhood of the critical point. ${ }^{8}$ In particular, the saturation temperature generally has the asymptotic form $\mathrm{T}_{\mathrm{S}}=\mathrm{T}_{\mathrm{C}}-$ const. $\times\left|\rho-\rho_{c}\right|^{1 / \beta}$, where $1 / \beta \approx 3$, for $\rho \rightarrow \rho_{c}$. Moreover, this "cubic" behavior near the critical points is not confined to an infinitesimal region around the critical point. For instance, as early as 1945 Guggenheim $^{13}$ found that

$$
\rho_{\ell} / \rho_{\mathrm{C}}=1+\frac{7}{4}\left(1-\mathrm{T}_{\mathrm{S}} / \mathrm{T}_{\mathrm{C}}\right)^{1 / 3}+\frac{3}{4}\left(1-\mathrm{T}_{\mathrm{S}} / \mathrm{T}_{\mathrm{C}}\right)
$$

and

$$
\rho_{\mathrm{g}} / \rho_{\mathrm{c}}=1-\frac{7}{4}\left(1-\mathrm{T}_{\mathrm{S}} / \mathrm{T}_{\mathrm{c}}\right)^{1 / 3}+\frac{3}{4}\left(1-\mathrm{T}_{\mathrm{S}} / \mathrm{T}_{\mathrm{c}}\right)
$$

provide a good approximation to $\rho_{\ell}$ and $\rho_{\mathrm{g}}$ for $\mathrm{T} / \mathrm{T}_{\mathrm{c}}$ in the range $(0.6,1)$ for many simple fluids. 
Although subsequent experimental work has shown that $\beta$ is not precisely equal to $1 / 3$ and that the true nonanalytic features of the equation of state are confined to a very small region about the critical point, it is clear that many coexistence curves of real fluids are basically "cubic." That is $\mathrm{T}_{\mathrm{S}}-\mathrm{T}_{\mathrm{C}} \approx\left|\rho-\rho_{\mathrm{C}}\right|^{3}$ is a good approximation over an appreciable range of $\left|\rho-\rho_{\mathrm{C}}\right|$ values. Our algorithm, on the other hand, always produces Eq. (1), a Taylor series for $\mathrm{T}_{\mathrm{S}}-\mathrm{T}_{\mathrm{C}}$ in $\rho-\rho_{\mathrm{C}}$ (not $\left|\rho-\rho_{\mathrm{C}}\right|$, and this is important). However, once one is able to deal analytically with the first dozen terms or so of Eq. (1), as we do here, one can easily produce coefficients such that polynomial (or Padé) approximants that result from the use of Eq. (1) rival Eqs. (60) and (61) in accuracy except in a very small neighborhood of $\left(\rho_{c}, T_{c}\right)$. To illustrate this point, we have included Figs. 5 and 6 . Fig. 5 shows a fit to the coexistence-curve shape defined by Guggenheim's approximation using Eq. (1) with $\mathrm{T}_{\mathrm{i}}=0$ for $\mathrm{i}>10$. Fig. 6 shows a fit to the simpler cubic equation of state $\mathrm{T}_{\mathrm{S}}=\mathrm{T}_{\mathrm{C}}-$ const $\times\left|\rho-\rho_{\mathrm{C}}\right|^{3}$ that is relevant to ferromagnetic substances with a simple Curie point for which $\rho-\rho_{C}$ has the significance of magnetization per atomic site $\mathrm{M}$, and one has exact symmetry in $\mathrm{M}$ about $\mathrm{M}=0$. Here Eq. (1) with $\mathrm{T}_{\mathrm{i}}=0$ for $\mathrm{i}>\mathrm{s}$ already produces an excellent overall fit. We defer to a future publication the details associated with finding the coefficients of such fits, and of considering the equations-of-state that can be related to them.

\section{ACKNOWLEDGMENTS}

The authors gratefully acknowledge the Office of Basic Energy Research (U.S.D.E) for its support. 


\section{APPENDIX 1}

The Gibbs-Duhem equation provides a connection between derivatives of $\mu$ and $\mathrm{p}$. Since

$$
\mathrm{d} \mu=\frac{1}{\rho} \mathrm{dp}, \text { at constant } \mathrm{T},
$$

it follows that

$$
(\partial \mu / \partial \rho)_{\mathrm{T}}=\frac{1}{\rho}(\partial \mathrm{p} / \partial \rho)_{\mathrm{T}}
$$

This relation holds for all $\mathrm{T}$ and $\rho$. Denoting $\left(\partial^{\mathrm{k}} \mu / \partial \rho^{\mathrm{k}}\right)_{\mathrm{T}}$ by $\mu_{\mathrm{k}}$ and $\left(\partial^{\mathrm{k}} \mathrm{p} / \partial \rho^{\mathrm{k}}\right)_{\mathrm{T}}$ by $\mathrm{p}_{\mathrm{k}}$, we have

$$
\rho \mu_{1}=\mathrm{p}_{1}
$$

Operating on Eq. (A3) with $(\partial / \partial \rho)_{\mathrm{T}}$ we obtain

$$
\mu_{1}+\rho \mu_{2}=\mathrm{p}_{2}
$$

Repeating this operation $\mathrm{k}$ times yields

$$
(\mathrm{k}-1) \mu_{\mathrm{k}-1}+\rho \mu_{\mathrm{k}}=\mathrm{p}_{\mathrm{k}}
$$

At the point $\rho=\rho_{\mathrm{C}}=1$ we have 


$$
\mu_{\mathrm{k}}=\mathrm{p}_{\mathrm{k}}-(\mathrm{k}-1) \mu_{\mathrm{k}-1}
$$

or

$$
\mu_{k}=\sum_{j=0}^{k-1} \frac{(-1)^{j}(k-1) !}{(k-1-j) !} p_{k-j}
$$

Taking the $\mathrm{n}^{\text {th }}$ temperature derivative of Eq. (A7) and dividing by $\mathrm{k}$ ! $n$ ! we obtain Eq. (17):

$$
\begin{aligned}
c_{k, n}= & \sum_{j=0}^{k-1} \frac{(-1)^{j}(k-1) !}{(k-1-j) !} \frac{(k-j) !}{k !} q_{k-j, n} \\
& =\sum_{j=0}^{k-1} \frac{(-1)^{j}(k-j)}{k} q_{k-j, n},
\end{aligned}
$$

where $\mathrm{q}_{\mathrm{k}, \mathrm{n}}$ and $\mathrm{c}_{\mathrm{k}, \mathrm{n}}$ are defined by Eqs. (8) and (9). 


\section{APPENDIX 2}

$$
\begin{aligned}
& \lambda_{\mathrm{n}, \mathrm{s}} \text { is determined by } \\
& \sum_{s=2 n}^{\infty} \lambda_{n, s} \delta x^{s}=\left(T_{2} \delta x^{2}+T_{3} \delta x^{3}+\cdots\right)^{n} \\
& =\mathrm{T}_{2}^{\mathrm{n}} \delta \mathrm{x}^{2 \mathrm{n}}\left(1+\frac{\mathrm{T}_{3}}{\mathrm{~T}_{2}} \delta \mathrm{x}+\frac{\mathrm{T}_{4}}{\mathrm{~T}_{2}} \delta \mathrm{x}^{2}+\cdots\right)^{\mathrm{n}} \\
& =\mathrm{T}_{2}^{\mathrm{n}} \delta \mathrm{x}^{2 \mathrm{n}} \sum_{\mathrm{k}_{1}=0}^{\mathrm{n}}\left[\begin{array}{l}
\mathrm{n} \\
\mathrm{k}_{1}
\end{array}\right] \mathrm{A}^{\mathrm{k}_{1}}
\end{aligned}
$$

where

$$
A=\frac{T_{3}}{T_{2}} \delta x+\frac{T_{4}}{T_{2}} \delta x^{2}+\cdots
$$

Applying the binomial theorem repeatedly we obtain

$$
\begin{aligned}
& \sum_{\mathrm{s}=2 \mathrm{n}}^{\infty} \lambda_{\mathrm{n}, \mathrm{s}} \delta \mathrm{x}^{\mathrm{s}}=\sum_{\mathrm{k}_{1}=0}^{\mathrm{n}} \sum_{\mathrm{k}_{2}=0}^{\mathrm{k}_{1}} \sum_{\mathrm{k}_{3}=0}^{\mathrm{k}_{2}} \cdots\left[\begin{array}{l}
\mathrm{n} \\
\mathrm{k}_{1}
\end{array}\right]\left[\begin{array}{l}
\mathrm{k}_{1} \\
\mathrm{k}_{2}
\end{array}\right]\left[\begin{array}{l}
\mathrm{k}_{2} \\
\mathrm{k}_{3}
\end{array}\right] \cdots
\end{aligned}
$$

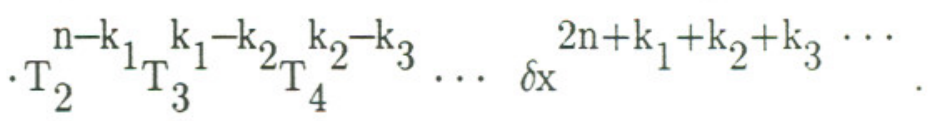


Similarly,

$$
\begin{aligned}
& \sum_{j=n}^{\infty} \theta_{n, j} \delta x^{j}=\left(-\delta x+y_{2} \delta x^{2}+y_{3} \delta x^{3}+\cdots\right)^{n} \\
& =\sum_{\mathrm{k}_{1}=0}^{\mathrm{n}} \sum_{\mathrm{k}_{2}=0}^{\mathrm{k}_{1}} \sum_{\mathrm{k}_{3}=0}^{\mathrm{k}_{2}} \cdots(-1)^{\mathrm{n}+\mathrm{k}_{1}} 1\left[\begin{array}{l}
\mathrm{n} \\
\mathrm{k}_{1}
\end{array}\right]\left[\begin{array}{l}
\mathrm{k}_{1} \\
\mathrm{k}_{2}
\end{array}\right]\left[\begin{array}{l}
\mathrm{k}_{2} \\
\mathrm{k}_{3}
\end{array}\right] \cdots \\
& \cdot \mathrm{y}_{2}{ }_{1}-\mathrm{k}_{2} \mathrm{y}_{3} \mathrm{k}_{2}-\mathrm{k}_{3} \mathrm{y}_{4} \mathrm{k}_{3}-\mathrm{k}_{4} \ldots \mathrm{x}^{\mathrm{n}+\mathrm{k}_{1}+\mathrm{k}_{2}+\mathrm{k}_{3} \cdots} .
\end{aligned}
$$




\section{REFERENCES}

1. To be more precise, we mean the class of one-component fluid models for which the pressure and chemical potential are analytic functions in a neighborhood of the critical point.

2. G. Fescos, Series solutions to the dew/bubble conditions for two polydisperse fluid models, M. S. Thesis, Department of Mechanical Engineering, SUNY at Stony Brook (1988).

3. J. M. Kincaid, G. Fescos, and G. Morrison, Int. J. Thermophys. 10, 75 (1989).

4. J. M. Kincaid, K. B. Shon, and G. Fescos, J. Stat. Phys. 57, 937 (1989).

5. J. M. Kincaid, M. Azadi, G. Fescos, L. Pellizzi, and K. B. Shon, J. Chem Phys. 90, 4454 (1989).

6. G. A. Baker, Jr., Essentials of Padé Approximants (Academic Press, New York, 1975). D. L. Hunter and G. A. Baker, Jr., Phys. Rev. B7, 3346 (1973).

7. L. D. Landau, Zh. Eksp. Teor. Fiz. 7, 19, 637 (1937) [Collected Papers of L. D. Landau, D. ter Haar, ed. (pergamon, Oxford, 1965), No. 29].

8. H. E. Stanley, Introduction to Phase Transitions and Critical Phenomena (Oxford University Press, New York, 1971).

9. J. M. Kincaid and E. G. D. Cohen, Phys. Rep. 22C, 57 (1975).

10. The pressure and chemical potentials of an FCC hard-sphere solid were obtained from the papers of Alder et al. ${ }^{11}$ and Hall. ${ }^{12}$ By adding the "van der Waals tail" contributions to these equations of state we obtained equations of state for the solid phase. The triple point was located by solving the three-phase equilibrium conditions.

11. B. J. Alder, W. B. Hoover, and D. A. Young, J. Chem. Phys. 49, 3688 (1967).

12. K. Hall, J. Chem. Phys. 57, 2252 (1972).

13. E. A. Guggenheim, J. Chem. Phys. 13, 253 (1945). 


\section{TABLE I}

Coexistence Curve Series Coefficients, $\mathrm{T}_{\mathrm{i}}$

$$
\begin{aligned}
& \mathrm{T}_{2}=-\mathrm{q}_{3,0} / \mathrm{q}_{1,1} \\
& \mathrm{~T}_{3}=-\left(12 \mathrm{q}_{1,1} \mathrm{q}_{4,0}-\left(10 \mathrm{q}_{2,1}+4 \mathrm{q}_{1,1}\right) \mathrm{q}_{3,0}\right) /\left(15 \mathrm{q}_{1,1}^{2}\right) \\
& \mathrm{T}_{4}=-\left(144 \mathrm{q}_{1,1}^{2} \mathrm{q}_{4,0}^{2}+\left(-240 \mathrm{q}_{1,1} \mathrm{q}_{2,1}-96 \mathrm{q}_{2,2}^{2}\right) \mathrm{q}_{3,0} \mathrm{q}_{4,0}\right. \\
& \left.+\left(100 \mathrm{q}_{2,1}^{2}+80 \mathrm{q}_{1,1} \mathrm{q}_{2,1}+16 \mathrm{q}_{1,1}^{2}\right) \mathrm{q}_{3,0}^{2}\right) /\left(225 \mathrm{q}_{1,1}^{2} \mathrm{q}_{3,0}^{2}\right) \\
& \mathrm{T}_{5}=-\left(20250 \mathrm{q}_{1,1}^{3} \mathrm{q}_{3,0}^{3} \mathrm{q}_{6,0}+\left(\left(7875 \mathrm{q}_{1,1}^{2} \mathrm{q}_{2,1}-13725 \mathrm{q}_{1,1}^{3}\right) \mathrm{q}_{3,0}^{3}\right.\right. \\
& \left.-9450 q_{1,1}^{3} q_{3,0}^{2} q_{4,0}\right) q_{5,0}-18900 q_{1,1}^{2} q_{3,0}^{4} q_{4,1} \\
& +\left(6048 q_{1,1}^{4}-3024 q_{1,1}^{3} q_{3,0}\right) q_{4,0}^{3}+\left(\left(17640 q_{1,1}^{2} q_{2,1}+5544 q_{1,1}^{3}\right) q_{3,0}^{2}\right. \\
& \left.+\left(-25200 q_{1,1}^{3} q_{2,1}-1008 q_{1,1}^{4}\right) q_{3,0}\right) q_{4,0}^{2} \\
& +\left(-9450 q_{1,1}^{2} q_{3,0}^{3} q_{3,1}+28350 q_{1,1} q_{1,2} q_{3,0}^{4}\right. \\
& +\left(-23100 q_{1,1} q_{2,1}^{2}-3360 q_{1,1}^{2} q_{2,1}+4512 q_{1,1}^{3}\right) q_{3,0}^{3} \\
& \left.+\left(29400 q_{1,1}^{2} q_{2,1}^{2}+8400 q_{1,1}^{3} q_{2,1}-1344 q_{1,1}^{4}\right) q_{3,0}^{2}\right) q_{4,0} \\
& +\left(7875 q_{1,1} q_{2,1}+17325 q_{1,1}^{2}\right) q_{3,0}^{2} q_{3,1} \\
& +\left(15750 q_{1,1} q_{2,2}-23625 q_{1,2} q_{2,1}-17325 q_{1,1} q_{1,2}\right) q_{3,0}^{5} \\
& +\left(8750 q_{2,1}^{3}-1050 q_{1,1} q_{2,1}^{2}-5040 q_{1,1}^{2} q_{2,1}-2908 q_{1,1}^{3}\right) q_{3,0}^{4} \\
& \left.+\left(-10500 q_{1,1} q_{2,1}^{3}-6300 q_{1,1}^{2} q_{2,1}^{2}+336 q_{1,1}^{4}\right) q_{3,0}^{3}\right) /\left(23625 q_{1,1}^{4} q_{3,0}^{3}\right)
\end{aligned}
$$

The $\mathrm{q}_{\mathrm{i}, \mathrm{n}}$ are defined by Eq. (8). 
Table II

Equations of State and Their Critical Constants

van der Waals: $\quad \mathrm{p}=\mathrm{k}_{\mathrm{B}} \mathrm{T} /(\mathrm{v}-\mathrm{b})-\mathrm{a} / \mathrm{v}^{2}$,

$$
\mathrm{p}_{\mathrm{c}}=\mathrm{a} /\left(27 \mathrm{~b}^{2}\right), \mathrm{k}_{\mathrm{B}} \mathrm{T}_{\mathrm{c}}=8 \mathrm{a} /(27 \mathrm{~b}), \mathrm{v}_{\mathrm{c}}=3 \mathrm{~b}
$$

Dieterici:

$$
\begin{aligned}
& \mathrm{p}=\mathrm{k}_{\mathrm{B}} \mathrm{Texp}\left[-\mathrm{a} /\left(\mathrm{k}_{\mathrm{B}} \mathrm{Tv}\right)\right] /(\mathrm{v}-\mathrm{b}) \\
& \mathrm{p}_{\mathrm{c}}=\mathrm{a} \mathrm{e}^{-2} /\left(4 \mathrm{~b}^{2}\right), \mathrm{k}_{\mathrm{B}^{\mathrm{T}}} \mathrm{T}_{\mathrm{c}}=\mathrm{a} /(4 \mathrm{~b}), \mathrm{v}_{\mathrm{c}}=2 \mathrm{~b}
\end{aligned}
$$

Soave-Redlich-Kwong: $\quad \mathrm{p}=\mathrm{k}_{\mathrm{B}} \mathrm{T} /(\mathrm{v}-\mathrm{b})-\mathrm{a} /[\mathrm{v}(\mathrm{v}+\mathrm{b})]$

$$
\begin{aligned}
& \mathrm{p}_{\mathrm{c}}=\mathrm{a}\left(52^{2 / 3}+82^{1 / 3}-18\right) /\left[\left(2^{4 / 3}-2^{2 / 3}\right) \mathrm{b}^{2}\right], \\
& \mathrm{k}_{\mathrm{B}} \mathrm{T}_{\mathrm{c}}=3 \mathrm{a}\left(1+2^{2 / 3}-2^{4 / 3}\right) / \mathrm{b}, \quad \mathrm{v}_{\mathrm{c}}=\mathrm{b} /\left(2^{1 / 3}-1\right)
\end{aligned}
$$

Carnahan-Starling + "vdW" Attraction:

$$
\begin{aligned}
& \mathrm{p}=\frac{{ }^{6 \mathrm{k}_{\mathrm{B}}}}{\pi \sigma^{3}} \frac{\left(\eta+\eta^{2}+\eta^{3}-\eta^{4}\right)}{(1-\eta)^{3}}-\mathrm{a} \rho^{2}, \eta=\pi \sigma^{3} \rho / 6 \\
& \mathrm{p}_{\mathrm{C}}=0.15900528243669967\left(\mathrm{a} /\left(\pi^{2} \sigma^{6}\right)\right), \\
& \mathrm{k}_{\mathrm{B}} \mathrm{T}_{\mathrm{c}}=0.094328703133723809\left(6 \mathrm{a} /\left(\pi \sigma^{3}\right)\right) \\
& \rho_{\mathrm{c}}=0.13004438841924539\left(6 /\left(\pi \sigma^{3}\right)\right)
\end{aligned}
$$


TABLE III

\section{SERIES-EXPANSION COEFFICIENTS, $\left\{\mathrm{T}_{\mathrm{i}}\right\}$}

van der Waals

$\mathrm{T}(2) \quad-1 / 4$

$\mathrm{T}(3) \quad 1 / 20$

$\mathrm{T}(4) \quad-9 / 200$

$\mathrm{T}(5) \quad 193 / 7000$

$\mathrm{T}(6) \quad-1537 / 70000$

$\mathrm{T}(7) \quad 6009 / 350000$

$\mathrm{T}(8) \quad-174131 / 12250000$

$\mathrm{T}(9) \quad 4039291 / 336875000$

$\mathrm{T}(10) \quad-139209837 / 13475000000$

$\mathrm{T}(11) \quad 55422640939 / 6131125000000$

$\mathrm{T}(12) \quad-22317626143 / 2786875000000$

$\mathrm{T}(13) \quad 1099077458301 / 153278125000000$

$\mathrm{T}(14) \quad-69486569467703 / 10729468750000000$

$\mathrm{T}(15) \quad 10775040909775247 / 182400968750000000$
Dieterici

$-1 / 3$

$4 / 45$

$-92 / 675$

$4036 / 70875$

$-30676 / 354375$

$32524 / 759375$

$-35419988 / 558140625$

$9448380692 / 276279609375$

- 205370173612/4144194140625

$157375373183396 / 5656825001953125$

$-3371430216359228 / 84852375029296875$

$2601031623009524 / 115707784130859375$ 
TABLE III cont.

$\begin{array}{lcc} & \text { Soave-Redlich-Kwong } & \text { CS + "vdW attraction" } \\ \mathrm{T}(2) & -0.19580035065607 & -0.16410809499026 \\ \mathrm{~T}(3) & 0.075359368811780 & 0.064661354351862 \\ \mathrm{~T}(4) & -0.047528644539767 & -0.034615884039276 \\ \mathrm{~T}(5) & 0.031749700865006 & 0.025076864066853 \\ \mathrm{~T}(6) & -0.023633880245896 & -0.019121466775161 \\ \mathrm{~T}(7) & 0.018570218584632 & 0.015296691949842 \\ \mathrm{~T}(8) & -0.015182427164643 & -0.012663366769707 \\ \mathrm{~T}(9) & 0.012763993513279 & 0.010745343100846 \\ \mathrm{~T}(10) & -0.010957486604647 & -0.0092932435957978 \\ \mathrm{~T}(11) & 0.0095621644677698 & 0.0081596247330552 \\ \mathrm{~T}(12) & -0.0084549642218270 & -0.0072526937962850 \\ \mathrm{~T}(13) & 0.0075574335651872 & 0.0065124057076953\end{array}$


TABLE IV

Relative errors, CS+vdW CXC, for $\mathrm{T}_{\mathrm{s}}(\rho)$

$\begin{array}{lcclc}\mathrm{T}_{\mathrm{S}} & \Delta \mathrm{T}_{\mathrm{g}} & \Delta \mathrm{T}_{\mathrm{g}} & \Delta \mathrm{T}_{\ell} & \Delta \mathrm{T}_{\ell} \\ & \text { series } & {[6 / 8]} & \text { series } & \\ 16 / 8] & \\ .0000 & .0000 & .0000 & .0000 & .0000 \\ .9900 & .0000 & .0000 & .0000 & .0000 \\ .9800 & .0000 & .0000 & .0000 & .0000 \\ .9500 & .0000 & .0000 & .0000 & .0000 \\ .9000 & .0000 & .0000 & -.0008 & .0000 \\ .8500 & -.0005 & .0000 & -.0216 & .0000 \\ .8000 & -.0025 & .0000 & -.2324 & .0000 \\ .7500 & -.0087 & .0000 & -1.5707 & .0000 \\ .7000 & -.0230 & .0003 & -7.9402 & .0000 \\ .6500 & -.0501 & .0016 & -33.0285 & .0000 \\ .6000 & -.0954 & .0057 & -119.8672 & .0000 \\ .5500 & -.1637 & .0138 & -394.7849 & .0000 \\ .5000 & -.2598 & .0167 & -1214.3480 & .0000 \\ .4000 & -.5577 & -.0950 & -10218.3383 & -.0003\end{array}$

Values of $\rho_{\mathrm{g}}$ and $\rho_{\ell}$ were found, using the equal-areas rule, for the temperatures $\mathrm{T}_{\mathrm{S}}$ listed in the table. Using these values of the density $\mathrm{T}_{\mathrm{S}}\left(\rho_{\mathrm{g}}\right)$ and $\mathrm{T}_{\mathrm{S}}\left(\rho_{\ell}\right)$ are calculated using the 13-term series and a [6/8] Padé approximant. The relative errors are defined by $\Delta \mathrm{T}_{\mathrm{g}}=\left(\mathrm{T}_{\mathrm{s}}-\mathrm{T}_{\mathrm{s}}\left(\rho_{\mathrm{g}}\right) / \mathrm{T}_{\mathrm{S}}\right.$ and $\Delta \mathrm{T}_{\ell}=\left(\mathrm{T}_{\mathrm{s}}-\mathrm{T}_{\mathrm{s}}\left(\rho_{\ell}\right) / \mathrm{T}_{\mathrm{s}}\right.$. 
TABLE V

\section{Relative Errors of Saturation Properties for the CS + vdW Model}

$\begin{array}{lllll}\mathrm{T}_{\mathrm{S}} / \mathrm{T}_{\mathrm{c}} & \begin{array}{l}\Delta \rho_{\mathrm{g}}\left(\mathrm{T}_{\mathrm{S}}\right) \\ {[6 / 7]}\end{array} & \begin{array}{l}\Delta \rho_{\ell}\left(\mathrm{T}_{\mathrm{S}}\right) \\ {[6 / 5]}\end{array} & \begin{array}{l}\Delta \mathrm{p}_{\mathrm{S}}\left(\mathrm{T}_{\mathrm{S}}\right) \\ {[5 / 2]}\end{array} & \begin{array}{l}\Delta\left[\mathrm{h}\left(\mathrm{T}_{\mathrm{S}}\right) / \mathrm{T}_{\mathrm{S}}\right] \\ {[7 / 5]}\end{array} \\ 1.0000 & .0000 & .0000 & .0000 & .0000 \\ .9900 & .0000 & .0000 & .0000 & .0000 \\ .9800 & .0000 & .0000 & .0000 & .0000 \\ .9500 & .0000 & .0000 & .0000 & .0000 \\ .9000 & .0000 & .0000 & .0000 & .0000 \\ .8500 & .0000 & .0000 & .0000 & .0000 \\ .8000 & .0000 & .0000 & .0000 & .0000 \\ .7500 & .0000 & .0000 & .0000 & .0000 \\ .7000 & .0000 & .0000 & .0000 & .0000 \\ .6500 & -.0002 & .0000 & .0000 & .0000 \\ .6000 & -.0008 & .0000 & .0001 & .0001 \\ .5500 & -.0029 & .0000 & .0013 & .0001 \\ .5000 & -.0074 & .0000 & .0074 & .0001\end{array}$

The relative error of a quantity $f\left(T_{S}\right)$ is denoted $\Delta f\left(T_{S}\right)$ and is defined by $\Delta f\left(T_{S}\right)=\left(f_{\text {ex }}-\right.$ $\left.\mathrm{f}_{\mathrm{P}}\right) / \mathrm{f}_{\text {ex }}$, where $\mathrm{f}_{\mathrm{ex}}$ is the numerically exact value and $\mathrm{f}_{\mathrm{P}}$ is the value of the Padé approximant. 


\section{FIGURE CAPTIONS}

Fig. 1 The coexistence curve (CXC) of the van der Waals model in the temperature-density plane. (The units are such that $\mathrm{T}_{\mathrm{c}}=\rho_{\mathrm{c}}=1$.) The dots represent points on the CXC determined using the equal-areas rule; the 15-term series-expansion representation of the CXC is given by the dotted curve; the solid curve represents the [7/8] Padé approximant of the 15-term series. The Padé was constructed to ensure that the correct $\mathrm{T}=0$ result was obtined.

Fig. 2 The coexistence curve (CXC) of the Dieterici model in the temperature-density plane. (The units are such that $\mathrm{T}_{\mathrm{c}}=\rho_{\mathrm{c}}=1$.) The dots represent points on the CXC determined using the equal-areas rule; the 13-term series-expansion representation of the CXC is given by the dotted curve; the solid curve represents the [6/6] Padé approximant of the 13-term series.

Fig. 3 The coexistence curve (CXC) of the Soave-Redlich-Kwong model in the temperature-density plane. (The units are such that $\mathrm{T}_{\mathrm{c}}=\rho_{\mathrm{c}}=1$.) The dots represent points on the CXC determined using the equal-areas rule; the 13-term series-expansion representation of the CXC is given by the dotted curve; the solid curve represents the [6/6] Padé approximant of the 13-term series.

Fig. 4 The coexistence curve (CXC) of the Carnahan-Starling + vdW tail model in the temperature-density plane. (The units are such that $\mathrm{T}_{\mathrm{C}}=\rho_{\mathrm{C}}=1$.) The dots represent points on the CXC determined using the equal-areas rule; the 13-term series-expansion representation of the CXC is given by the dotted curve; the solid curve represents the [6/8] Padé approximant of the 13-term series. This Padé was constructed to ensure that the correct triple-point result was obtained.

Fig. 5 The "Guggenheim" coexistence curve in the temperature-density plane. (The units are such that $\mathrm{T}_{\mathrm{c}}=\rho_{\mathrm{c}}=1$.) The dots represent Eqs. (60) and (61); the solid curve is a tenth-order polynomial in $\left(\rho-\rho_{\mathrm{C}}\right)$, the coefficients of which were determined by a least squares criterion.

Fig. 6 A simple cubic coexistence curve in the temperature-density plane. (The units are such that $\mathrm{T}_{\mathrm{C}}=\rho_{\mathrm{C}}=1$.) The dots represent $\mathrm{T}_{\mathrm{S}}=1-\left|\rho-\rho_{\mathrm{C}}\right|^{3}$; the solid curve is an eighth-order polynomial in $\left(\rho-\rho_{\mathrm{C}}\right)$, the coefficients of which were determined by a least squares criterion. 
1. $b_{1}$

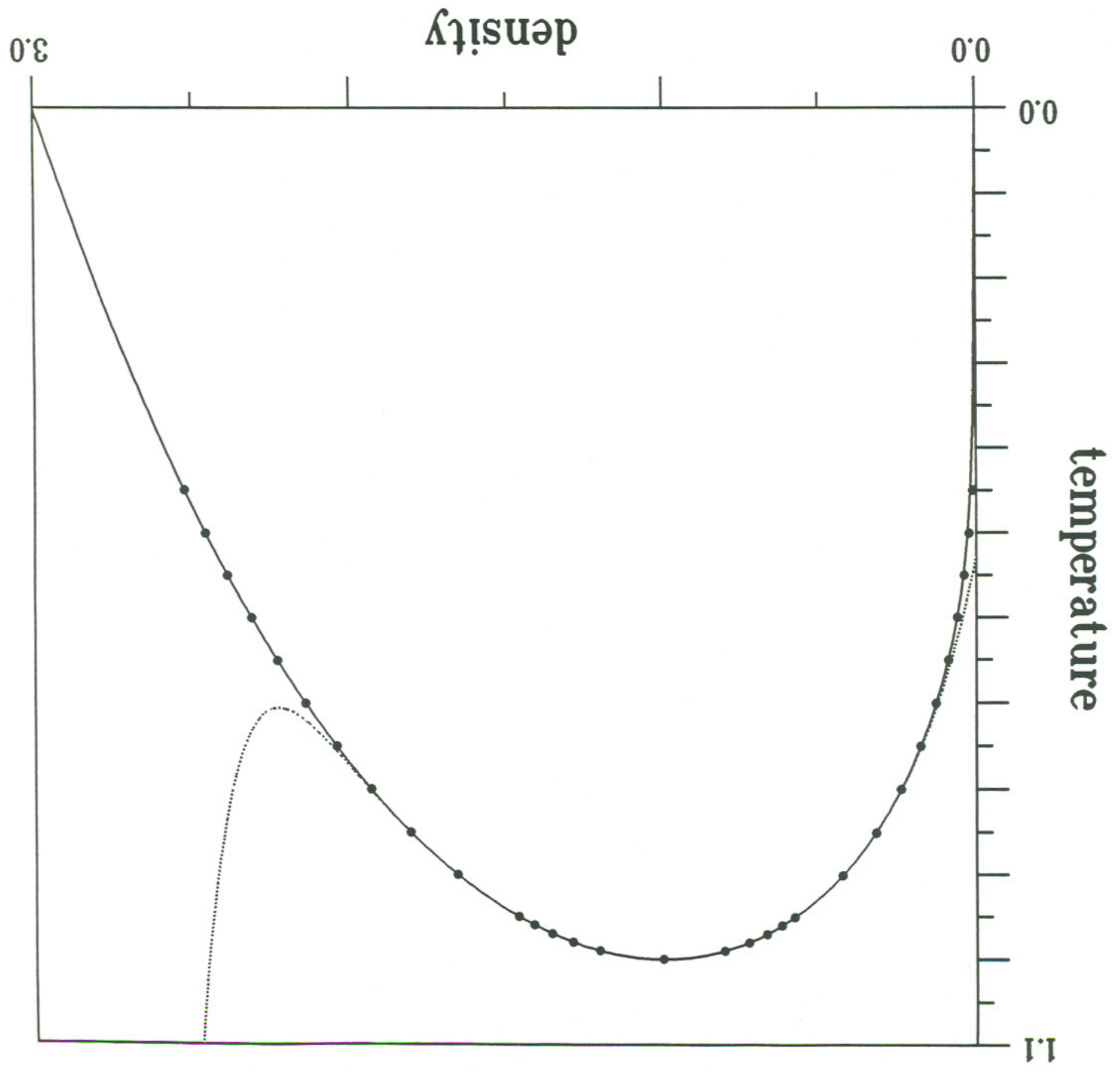


$2 \cdot b ! 1$

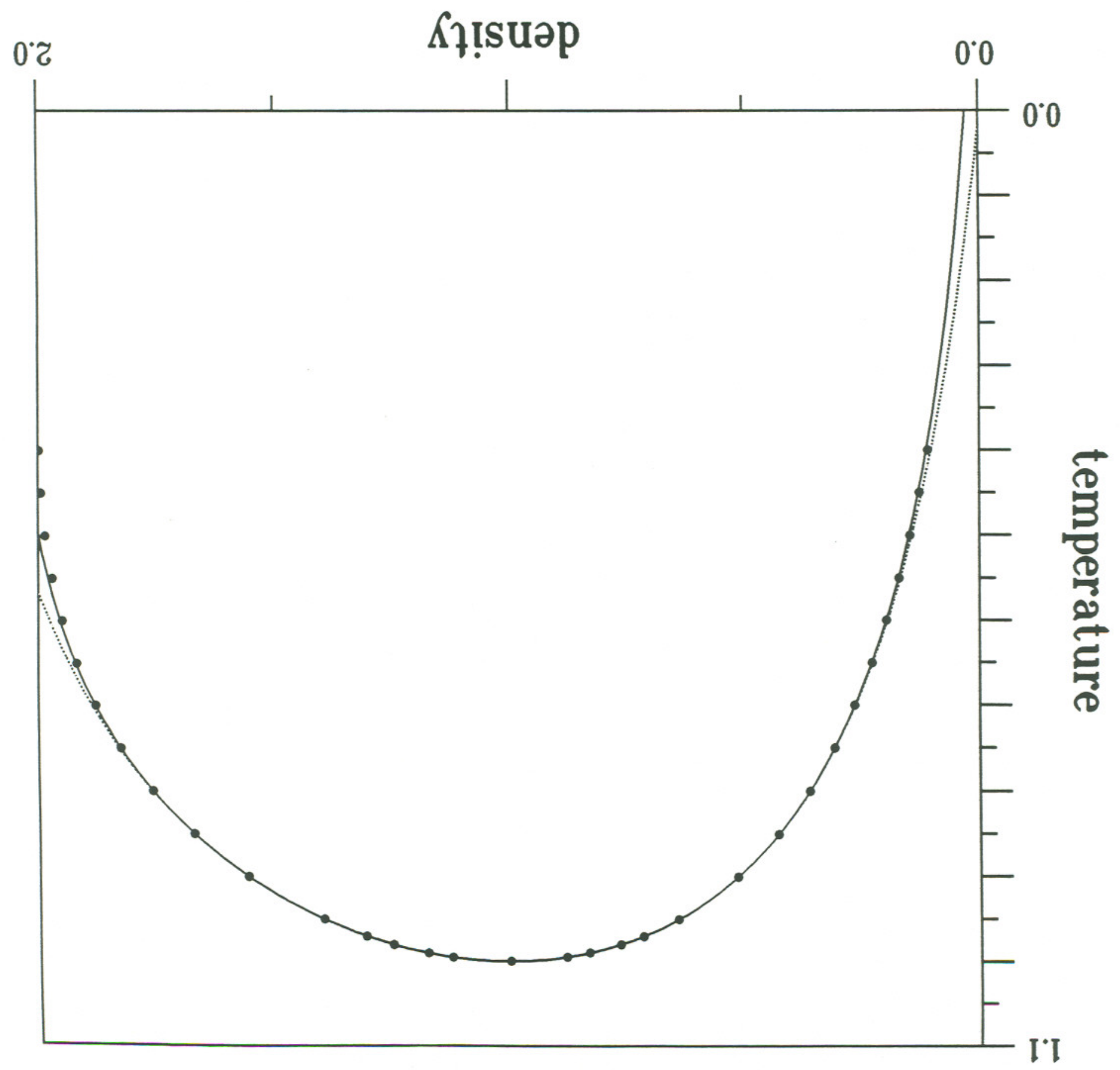




$$
\text { E. b! } 1
$$

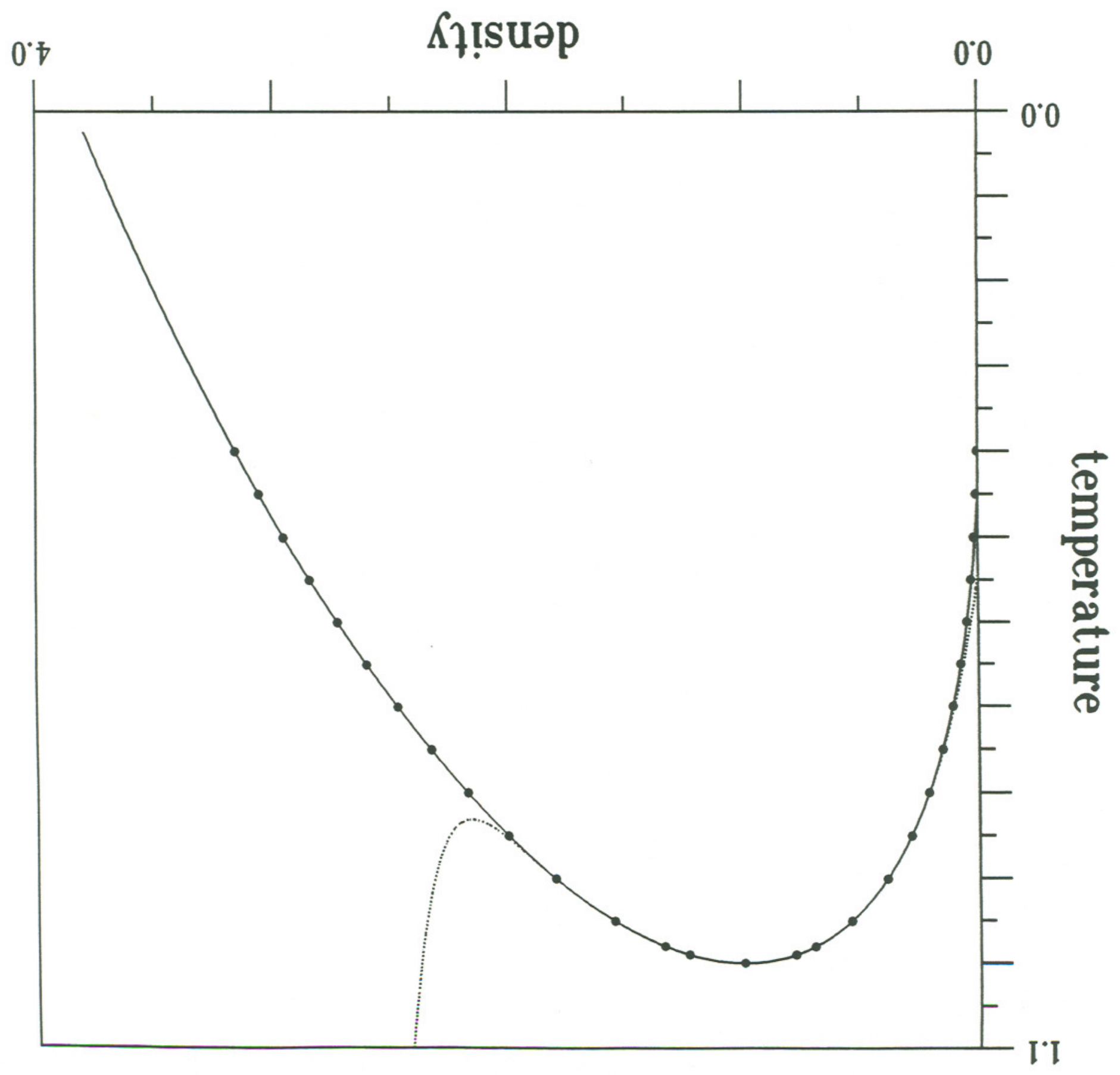




$$
\text { h. } b_{1} \cdot 1
$$

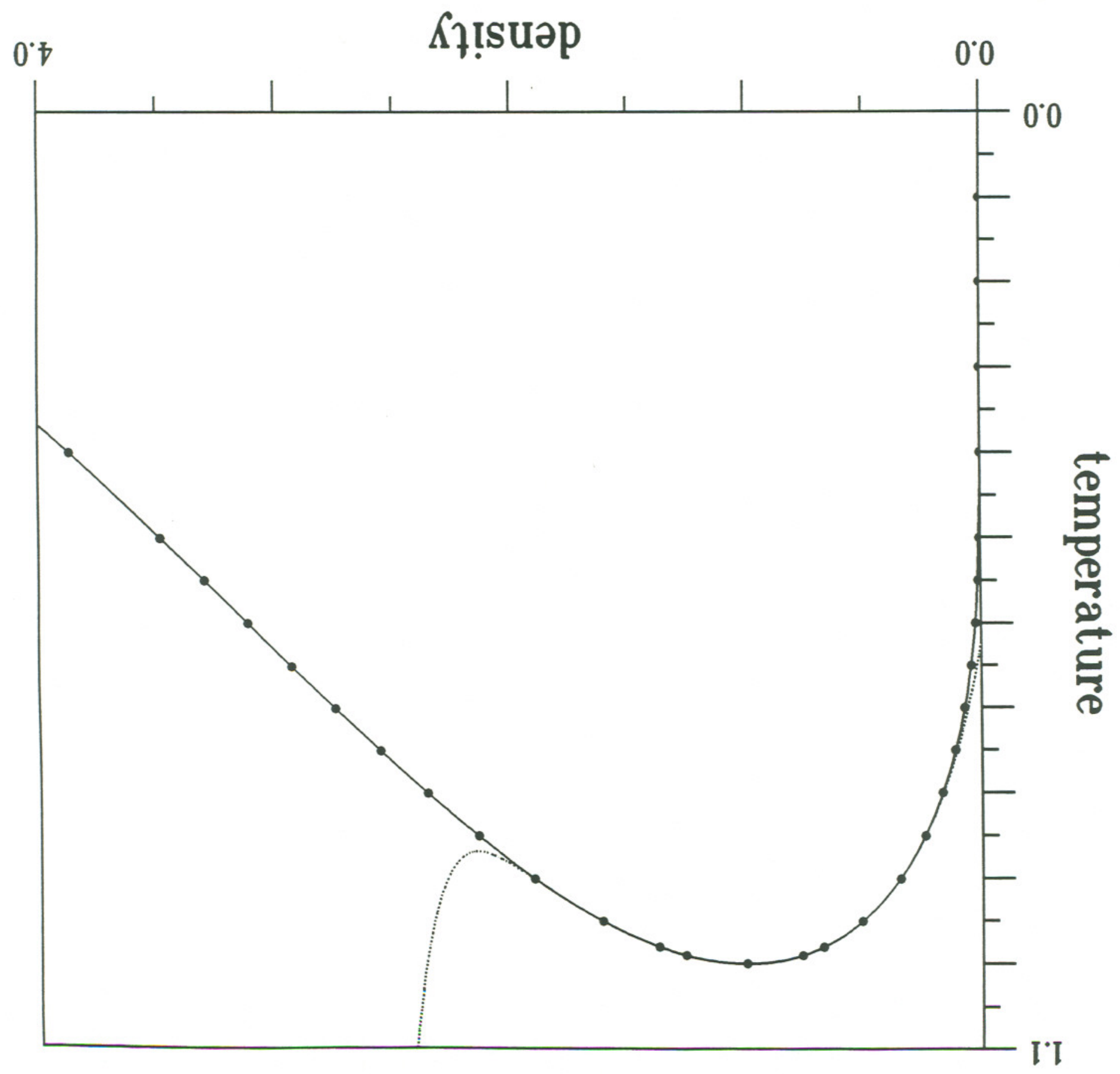


$5 \cdot b !-1$

$0^{\circ} \mathcal{E}$

Кำเงuəp

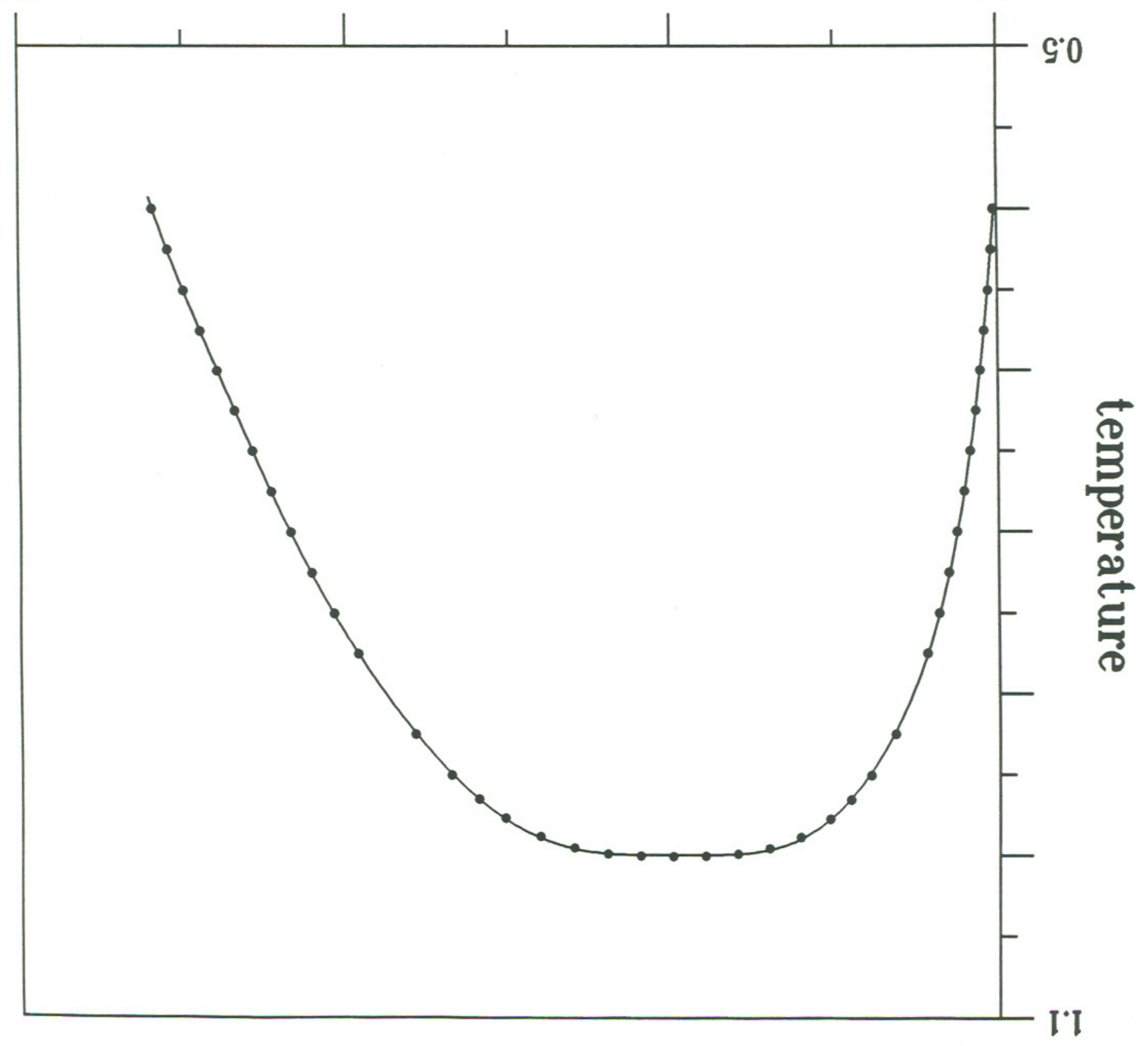


$9 \cdot b !=$

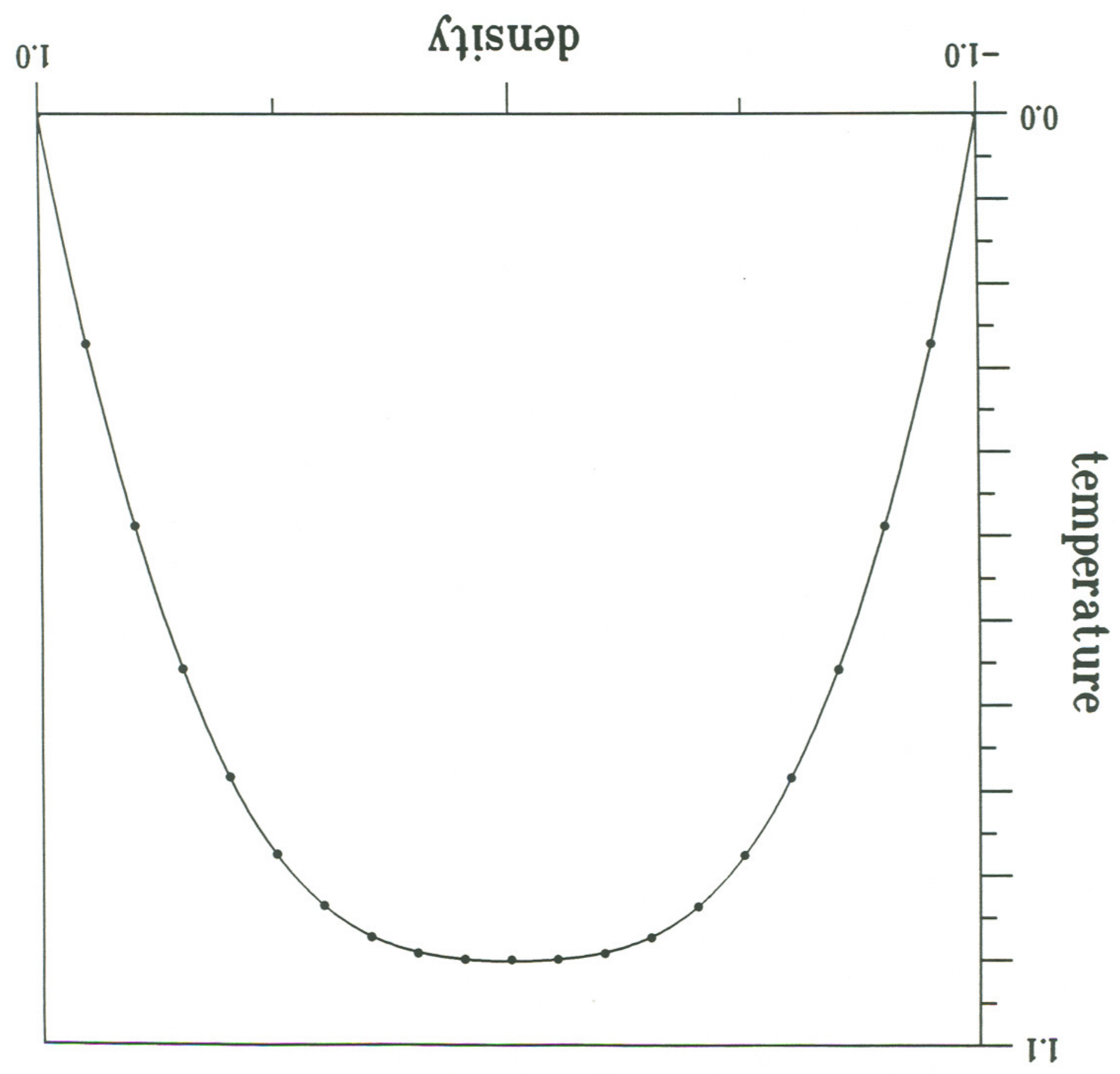


Kł! ISUәр

$J 000^{\circ} \varepsilon \quad 0009^{\circ} Z \quad 0000^{\circ} \zeta \quad 0009^{\circ} \mathrm{I} \quad 0000^{\circ} \mathrm{I} \quad 0009^{\circ} \quad 0^{\circ} 0$

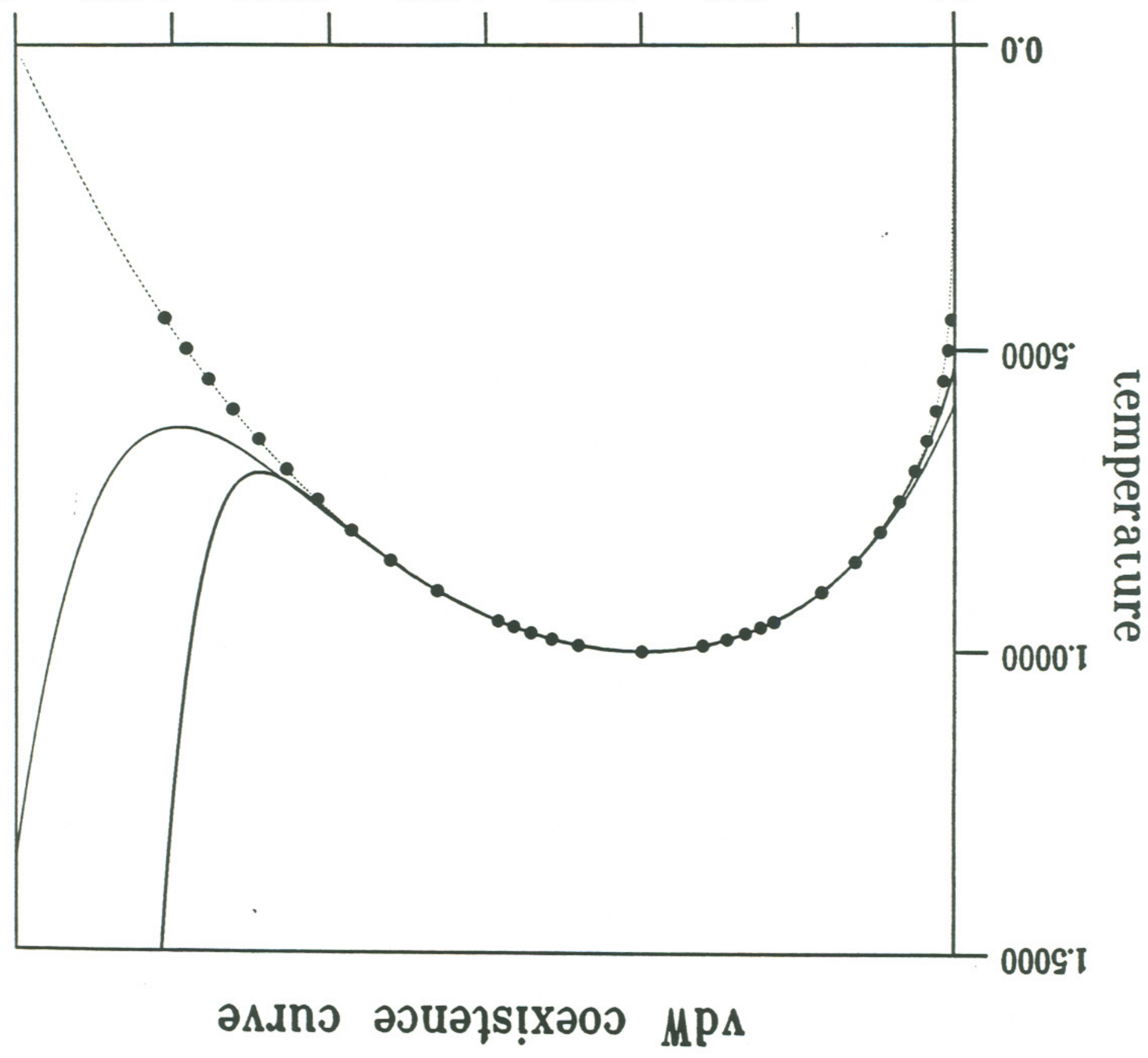




\section{Кา! เธวนр}

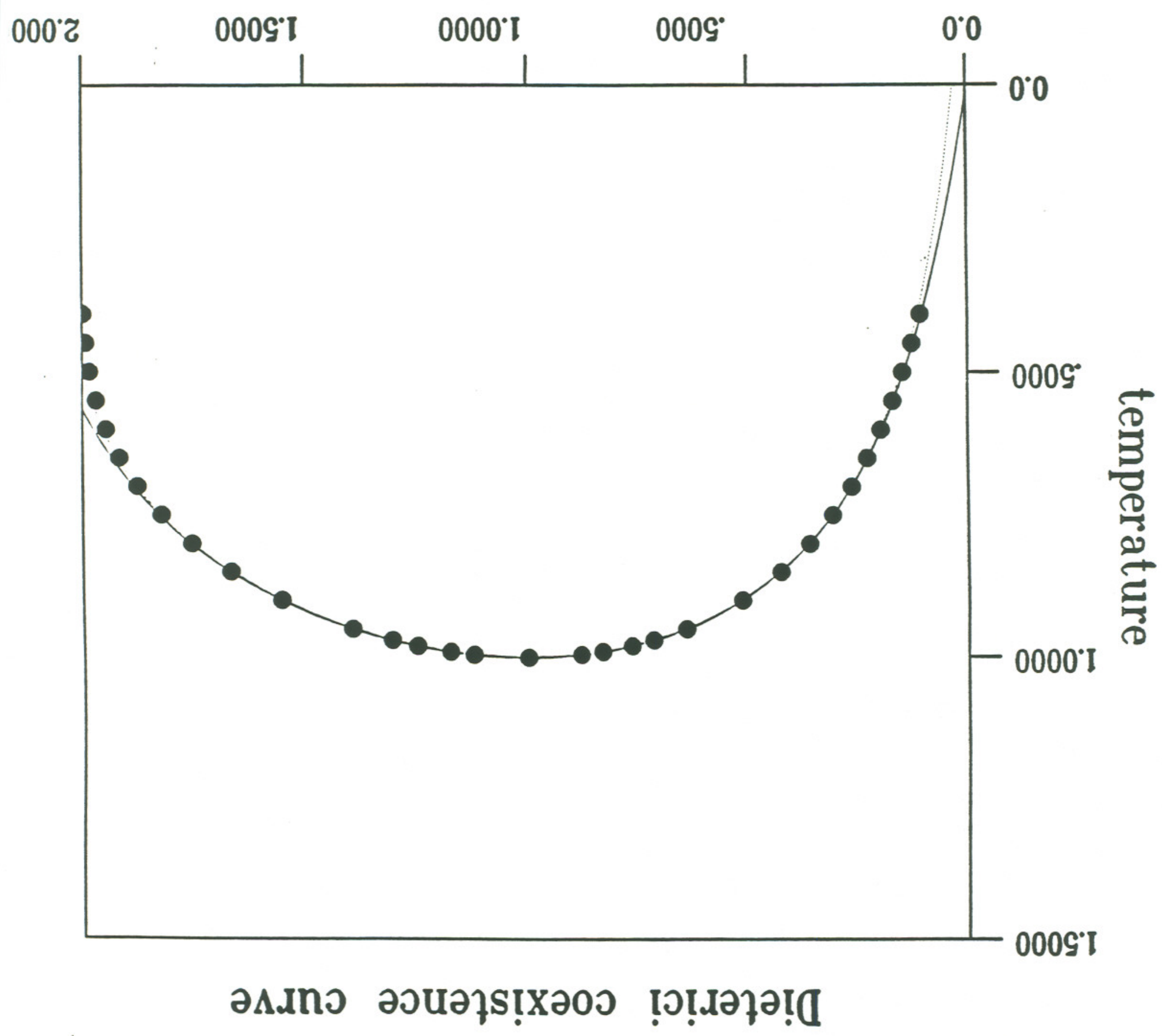




\section{cs-vdW coexistence curve}

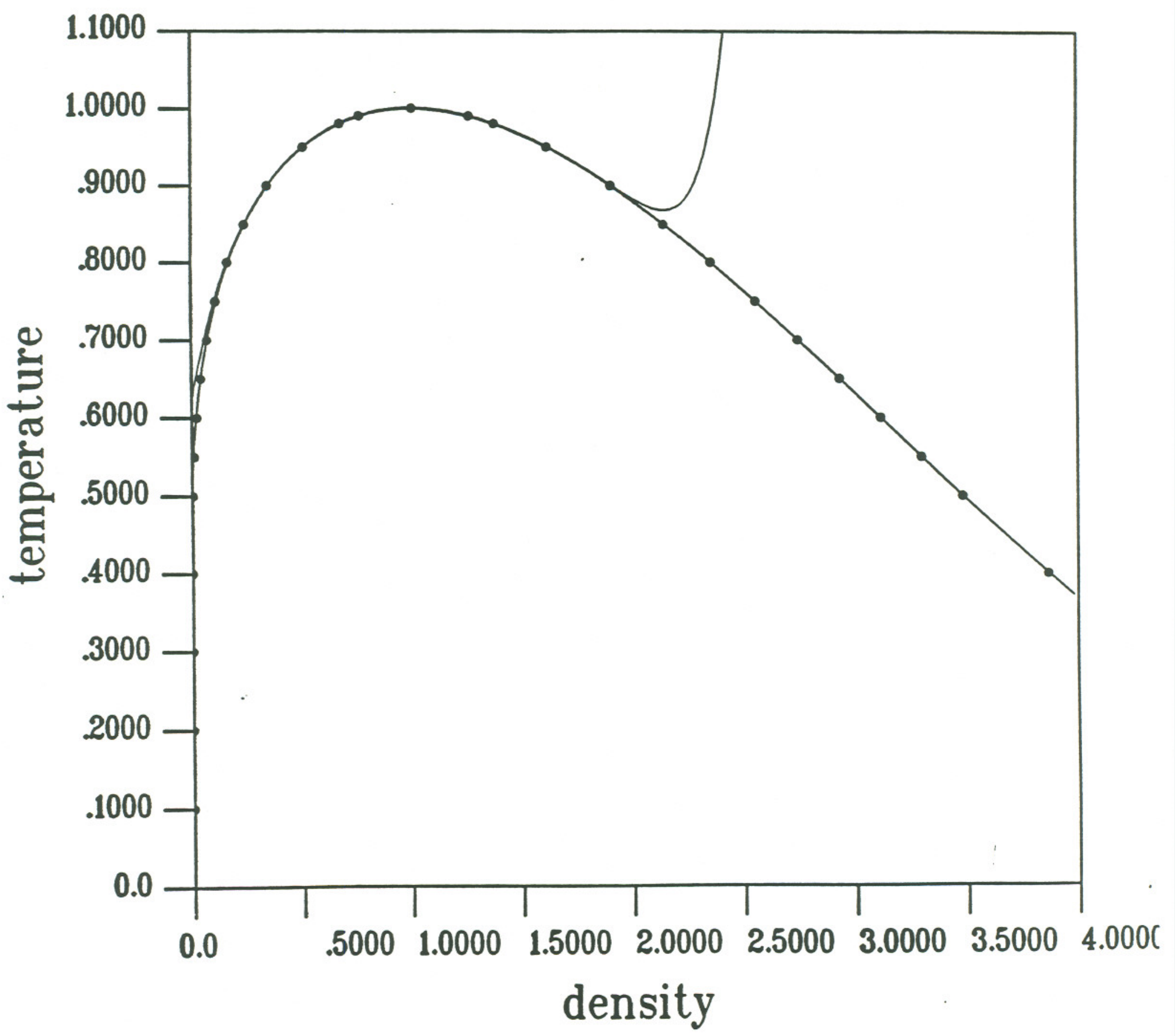

